\title{
Loan Transactions with Random Dates for the First and Last Periodic Instalments
}

\author{
María del Carmen Valls Martínez and Salvador Cruz Rambaud \\ Departamento de Economía y Empresa, Universidad de Almería, La Cañada de San Urbano s/n, 04120 Almería, Spain \\ Correspondence should be addressed to María del Carmen Valls Martínez; mcvalls@ual.es
}

Received 9 March 2016; Accepted 11 July 2016

Academic Editor: Chin-Chia Wu

Copyright ( 2016 M. C. Valls Martínez and S. Cruz Rambaud. This is an open access article distributed under the Creative Commons Attribution License, which permits unrestricted use, distribution, and reproduction in any medium, provided the original work is properly cited.

Usually, loan transactions contracted in practice are nonrandom; that is to say, all amounts received (principal) and paid (period instalments) by the borrower are previously agreed with the lender, as well as their respective dates. In this paper, two new alternative loan models are introduced, depending on whether the borrower survives or not to fulfil all repayment obligations. In this way, either the initial or the final date of repayments can be subject to this contingency. Additionally, the different parameters of such random transactions are determined, as well as several measures of profitability/cost for the lender/borrower, respectively. These transactions can be attractive for both the lender and the borrower, which therefore make them worthy of consideration and subsequent implementation for the benefit of both parties.

\section{Introduction}

It is well known that the current economic and financial situation brought about by the crisis in the construction sector has favoured the design and availability of new banking products [1, pp. 53-60] and, more specifically, mortgage loans [2]. In effect, on the one hand, there exists an increasing concern about the purchasing power of future generations. This means that those who contract a mortgage loan [3] are in favour of any repayment agreement which is finalised in the case of their premature death and does not transfer to their descendants. Additionally, this situation can be of particular interest to banking institutions because it can stimulate the provision of certain mortgage loans (generally agreed to be repaid over a long-term period) by persons of advanced age. Thus, the first objective of this paper is to present a novel kind of loan which can be attractive for elderly people because the outstanding principal is cancelled when they die and consequently it does not suppose an economic liability for future generations. This takes into account the fact that the current situation of an uncertain labour market in all modern economies mainly affects young people.

On the other hand, the opposite scenario is also possible, promoting the design of loans which adapt to the possible financial difficulties of the contracting parties themselves. This paper therefore gives consideration to two possible situations:

(1) Where premature death of the contract holder causes the mortgage repayment obligations to pass to those who inherit the mortgaged property (inverse mortgage). In this case, the property itself is a potential guarantee that the outstanding amount of mortgage repayment can be met.

(2) Where those who inherit a mortgaged property cannot, or do not wish to, make an immediate sale to pay off the outstanding mortgage but do not have sufficient liquidity to face up to their inherited financial obligations.

Observe that the first situation means that the initial payments are assured and the final payments are random, whilst the second situation leads to random initial payments but the final ones are assured [4]. Once we have explained the reasons for introducing these two novel random transactions, we then proceed, in the paragraphs which follow, to specify their financial conditions and main characteristics.

In traditional loan transactions, the amounts repaid by the borrower to amortize the principal and the corresponding 
periodicity of repayment are established at the beginning of the loan [5]. However, some loans are possible in which the dates for the initial and final instalment payments are random, where the transaction duration would be subject to the occurrence of an eventuality. There follows an example of each one of these possible innovative transactions:

(I) Loans where the payment of the first instalment is fixed and the payment of the last one is random. In this case, the amounts which amortize the received principal start to be repaid on an agreed date following the granting of the mortgage loan. Nevertheless, the duration depends on the survival period of the borrower [6]. This would be the case of a person who requests a loan to be amortized with the revenues coming from a life insurance policy, for example. Thus, if the borrower dies, the periodic payments would terminate. More generally, this situation occurs when a person of a certain age requests a loan with the intention of not leaving the debt to his/her heirs in a will.

Nowadays and in practice, this is similar to mortgage insurance [7] required by the financial institution in case of death or total incapacity of the borrower. In fact, they are two different financial transactions where the risk is assumed by the insurance company. Nevertheless, the transaction presented here differs in that the risk is assumed by the lender.

(II) Loans where the date of the first payment is random and the final one is fixed. In this case, the instalments which amortize the received principal start to be paid at an uncertain moment after the agreed instant at which the principal is provided by the lender, but the final instant is explicit in the mortgage contract. This would be the case of a person who requests a loan to be amortized by his/her heirs when he/she dies. As the instant of death of the contract holder is not previously known, although the probability factor can be calculated, the date of the initial instalment will be random.

In practice, this is similar to the so-called inverse mortgage, in which the borrower offers his/her house as a guarantee [8] and, as a consequence, he/she receives a single amount (the loan principal). Starting from the date of the borrower's death, this amount will be repaid, together with the accrued interest, by his/her heirs. However, currently, in an inverse mortgage, in order to obtain a fiscal advantage from the inheritance, the principal must be amortized with a single payment, unless at this moment the heirs agree with the lender on another loan transaction which replaces the first one. What is proposed here consists of a single loan transaction in which the lender assumes the risk of a repayment by the heirs, depending on the moment of death of the contracting party.

All these innovative loan agreements are independent of the principal repayment methods [9] which are common within the loan amortization models (French method, constant principal repaid method, American method, etc.). In effect, the contracting party of a mortgage loan [10-12] can use any of the traditional methods to repay the loan, among which we can cite the French method (equal payments for all periods) which is the most usual, the constant principal repaid method, and the American method [13]. Moreover, these methods can be combined with other financial procedures, such as interest-only periods and fixed or variable interest rates [14].

Finally, observe that the issue considered in this paper is included in a wide variety of mortgage loans labelled, in general, "flexible loans" which the credit institutions have recently started to offer (see [15, pp. 173-189] and [16, pp. 829853]). In addition to the wide range of offers described in the previous paragraph, there exist other possibilities of mortgage loan amortization which have not yet been defined and which can prove very interesting, due to their flexibility, depending on the economic situation of the borrower.

This paper is organized as follows. After describing in the Introduction the context of our research, in Sections 2 and 3, we will analyse the two innovative kinds of loan transaction which have been proposed. Finally, Section 4 summarizes and concludes the paper.

\section{Amortization of a Loan Transaction Where the First Repayment Instalment Is Fixed and the Last Is Random}

Let us consider a loan transaction in which the borrower receives the principal $C_{0}$ at instant 0 to be repaid by means of $n$ periodic amounts $a_{s}$, on specified dates $s(s=1,2, \ldots, n)$. If the last payment is subject to a possible contingency, the borrower would have to pay a series of amounts $a_{s}$ greater than those corresponding to a similar transaction which is not subject to uncertainty. Thus, we propose the following equation of financial random equivalence at instant 0 , by using the exponential discount function with variable discount rate according to the corresponding period:

$$
C_{0}=\sum_{s=1}^{n} a_{s} \cdot \prod_{h=1}^{s}\left(1+i_{h}\right)^{-1} \cdot\left(1+r_{h}\right)^{-1}
$$

where $r_{h}$ represents an additional payment to the lender to cover the element of risk in the transaction.

When the contingency is the death of the borrower, obviously, $r_{h}$ is the risk that the borrower dies and consequently the debt payment disappears to the detriment of the lender. Thus, by considering the survival of the borrower, one has (see [17])

$$
1+r_{h}=\frac{1}{{ }_{1} p_{h-1}}=\frac{l_{h-1}}{l_{h}},
$$

${ }_{1} p_{h-1}$ being the probability that a person aged $h-1$ reaches the age $h$ and $l_{z}$ being the number of persons who survive beyond the age $z$.

By considering (1) and (2) and defining $l_{s} / l_{0}:=p_{s}$, with $p_{s}$ being the probability of survival at instant $s$, one has

$$
C_{0}=\sum_{s=1}^{n} a_{s} \cdot p_{s} \cdot \prod_{h=1}^{s}\left(1+i_{h}\right)^{-1}
$$


which coincides with Gil Luezas and Gil Peláez [18] or Gil Peláez [19], by considering the exponential discount function.

Observe that the subscript $s$ denotes the instant at which the corresponding payment is due, calculated from the start of the financial transaction. Therefore, $l_{0}$ is the number of living persons of the same age as the borrower when he/she contracted the loan. Thus, for instance, if the borrower is 60 at the formal contract date, $l_{0}$ is the number of persons of the same generation who reach such age. Analogously, $l_{8}$ is the number of persons of this generation who reach 68 .

The outstanding principal at an intermediate instant $k$, denoted by $C_{k}$, is the (outstanding) balance still to be repaid by the borrower to pay off the loan. It can be calculated using three different methods [20, pp. 249-256].

(I) Prospective Method (according to the Future Periodic Instalments to Be Paid, i.e., from Instant $k$ to the Last Payment Due $n)$. One has

$$
C_{k}=\sum_{s=k+1}^{n} a_{s} \cdot \prod_{h=k+1}^{s}\left(1+i_{h}\right)^{-1} \cdot\left(1+r_{h}\right)^{-1}
$$

from which simple algebra shows that

$$
C_{k}=\frac{1}{p_{k}} \cdot \sum_{s=k+1}^{n} a_{s} \cdot p_{s} \cdot \prod_{h=k+1}^{s}\left(1+i_{h}\right)^{-1} .
$$

(II) Retrospective Method (according to the Periodic Amounts Already Paid by the Borrower from the Commencement to Instant $k)$. Starting from (4), one has

$$
\begin{aligned}
C_{k}= & \sum_{s=k+1}^{n} a_{s} \cdot \prod_{h=1}^{s}\left(1+i_{h}\right)^{-1} \cdot\left(1+r_{h}\right)^{-1} \cdot \prod_{h=1}^{k}\left(1+i_{h}\right) \\
& \cdot\left(1+r_{h}\right)
\end{aligned}
$$

that is to say,

$$
\begin{aligned}
C_{k}= & \prod_{h=1}^{k}\left(1+i_{h}\right) \cdot\left(1+r_{h}\right) \\
& \cdot\left[C_{0}-\sum_{s=1}^{k} a_{s} \cdot \prod_{h=1}^{s}\left(1+i_{h}\right)^{-1} \cdot\left(1+r_{h}\right)^{-1}\right],
\end{aligned}
$$

which can be simplified to

$$
\begin{aligned}
C_{k} & =\frac{1}{l_{k}} \cdot\left[C_{0} \cdot \prod_{h=1}^{k}\left(1+i_{h}\right) \cdot l_{0}\right. \\
& \left.-\left(\sum_{s=1}^{k-1} a_{s} \cdot l_{s} \cdot \prod_{h=s+1}^{k}\left(1+i_{h}\right)\right)\right]-a_{k},
\end{aligned}
$$

and, multiplying and dividing by $l_{0}$, finally one has

$$
\begin{aligned}
C_{k} & \\
= & \frac{1}{p_{k}} \\
& \cdot\left[C_{0} \cdot \prod_{h=1}^{k}\left(1+i_{h}\right)-\left(\sum_{s=1}^{k-1} a_{s} \cdot p_{s} \cdot \prod_{h=s+1}^{k}\left(1+i_{h}\right)\right)\right] \\
& -a_{k} .
\end{aligned}
$$

(III) Recursive Method (according to the Outstanding Principal Calculated at a Former Date). Starting from (8) for period $k+1$, this can be simplified using standard mathematical procedures, resulting in

$$
C_{k+1}=C_{k} \cdot\left(1+i_{k+1}\right) \cdot \frac{p_{k}}{p_{k+1}}-a_{k+1} .
$$

As previously indicated, if the loan amortization is subject to a contingency, the borrower would have to pay the amounts $a_{s}$ involved in the equation of financial random equivalence (3). However, if the transaction is not subject to this contingency, the corresponding amounts, $a_{s}^{\prime \prime}$, would verify the following familiar equation of financial equivalence at the start of the transaction:

$$
C_{0}=\sum_{s=1}^{n} a_{s}^{\prime \prime} \cdot \prod_{h=1}^{s}\left(1+i_{h}\right)^{-1} .
$$

By comparing (3) and (11), it can quite be simply observed that $a_{s}^{\prime \prime}<a_{s}$. Evidently, the difference between the two payments is exclusively due to the risk whereby this difference will be called the risk quota which will be denoted by $a_{s}^{\prime}$. Therefore,

$$
a_{s}^{\prime}:=a_{s}-a_{s}^{\prime \prime} .
$$

By considering (10) and (12), the additional amount that the borrower has to pay to the lender in each period due to assumed risk can be simplified as follows:

$$
a_{k+1}^{\prime}=C_{k} \cdot\left(1+i_{k+1}\right) \cdot \frac{p_{k}-p_{k+1}}{p_{k+1}} .
$$

Observe that $a_{s}^{\prime \prime}$, called the saving quota, is the part of the payment corresponding to a riskless transaction and, consequently, it is allotted to pay the interest of period $s\left(I_{s}\right)$ and the amortization of a part of the principal $\left(A_{s}\right)$ :

$$
a_{s}^{\prime \prime}=I_{s}+A_{s}=a_{s}-a_{s}^{\prime} .
$$

These random transactions can be agreed with constant or variable interest rates. Moreover, the amount of the periodic payment $\left(a_{s}\right)$ can be chosen and then the problem is to determine the principal $\left(C_{0}\right)$. Alternatively, once the principal $C_{0}$ is fixed, one can determine the periodic instalments $a_{s}$; finally, once $C_{0}$ and the saving quota $\left(a_{s}^{\prime \prime}\right)$ derived from (11) are fixed, the amount of the risk quota $\left(a_{s}^{\prime}\right)$ corresponding to each period can be determined, giving rise to a variable payment $a_{s}$. 
Example 1. Assume that, in 2013, a person aged 50 requests a loan of $€ 50,000$. In order to determine the risk, the financial entity applies the probability of survival corresponding to a person with the same age and sex (male) as the borrower (see tables PERM/F-2000P). According to this information, one can determine the periodic payments and the amortization schedule (observe that when the loan contract comes into force, the probability of survival is 1 because we are dealing with probabilities conditioned to the survival of the borrower at that moment). By applying the aforementioned survival tables, this person is expected to survive for a further 44 years, that is to say, to the age of 94 . By considering that the periodic amounts $a_{s}$ will be constant and that the transaction has been agreed with an annual variable interest rate of $9 \%$ for the first 5 years and that it will be updated every 5 years with an increase of $0.2 \%$, the different parameters of the loan transaction can be observed in Table 1 .

In this kind of transaction, it is usual to find some periods in which the amortization "is not regular." This means that, in these periods, the outstanding principal does not decrease as usual but increases since the corresponding periodic payments are less than the interest plus the risk quota for such periods. This situation can be observed in the first period of our example. As a result, the repaid principal is negative and consequently the outstanding principal is greater than $C_{0}$ during the first two years of the loan.

The risk quota is variable during the entire transaction. At the beginning of the loan, the risk is minimal but increases as the borrower becomes older. This is reasonable because this parameter must reflect the greater risk to the lender as the age of the borrower increases.

If the entire periodic instalments $a_{s}$ were allocated to the traditional amortization of the principal, it would be completely amortized before the expiration of the initially agreed loan; in our example, this would occur during the twenty-sixth year, since

$$
\begin{gathered}
\sum_{s=1}^{25} 1,028.41 \cdot \prod_{h=1}^{s}\left(1+i_{h}\right)^{-1}=9,957.38<10,000.00 \\
<10,056.32=\sum_{s=1}^{26} 1,028.41 \cdot \prod_{h=1}^{s}\left(1+i_{h}\right)^{-1} .
\end{gathered}
$$

In this case, the lender would make a greater profit which could compensate for the losses generated by other transactions in which the corresponding borrower dies earlier. These profits alone serve to make the implementation of these transactions particularly attractive [21].

In this type of random loan, the following average interest rates can be defined.

(1) Average Agreed Interest Rate. If the loan is agreed with a variable interest rate, it is interesting to know the average interest rate, $i_{m}$, resulting from the contract. By definition, this average is the rate which, when applied to all periods, makes the financial equivalence between the principal and the periodic instalments which amortize it possible. Thus, once the values of $C_{0}, a_{s}$, and $p_{s}$ satisfying (3) have been determined, the average interest rate can be derived from the following equation:

$$
C_{0}=\sum_{s=1}^{n} a_{s} \cdot p_{s} \cdot\left(1+i_{m}\right)^{-s}
$$

In Example 1, by considering that

$$
10,000.00=\sum_{s=1}^{44} 1,028.41 \cdot p_{s} \cdot\left(1+i_{m}\right)^{-s},
$$

the average interest rate of the loan transaction is $9.2451 \%$.

(2) True Net Interest Rate. Once the maturity of the financial transaction is known and consequently the number of payments, $k$, the true net interest rate, denoted by $i_{n, k}$, is the rate satisfying the following equation:

$$
\sum_{s=1}^{k} a_{s} \cdot \prod_{h=1}^{s}\left(1+i_{h}\right)^{-1}=\sum_{s=1}^{k} a_{s} \cdot\left(1+i_{n, k}\right)^{-s} .
$$

By considering the contract interest rate as the remuneration for the lent amount, the result of the transaction (profit or loss) measured in monetary units corresponding to the commencement of the loan period and for a duration of $k$ periods, $R_{0, k}$, is given by the difference:

$$
R_{0, k}=\sum_{s=1}^{k} a_{s} \cdot \prod_{h=1}^{s}\left(1+i_{h}\right)^{-1}-C_{0} .
$$

By considering (18) and (19), one has

$$
C_{0}+R_{0, k}=\sum_{s=1}^{k} a_{s} \cdot\left(1+i_{n, k}\right)^{-s},
$$

and this is the reason for labelling as net the value of $i_{n, k}$.

This rate is variable according to when the final instalment is paid. Thus, at the beginning of the transaction, one can only determine its expected average value, taking into account the fact that the probability of each duration $k$ and consequently of each rate is

$$
p_{k}-p_{k+1}
$$

Denoting by $d_{k}$ the number of persons, born in the same year as the borrower, who die between the ages of $k$ and $k+1$ [17, p. 273], one has

$$
d_{k}=l_{k}-l_{k+1} .
$$

The probability of death between the ages of $k$ and $k+1$ will be

$$
{ }_{1} f_{k}=\frac{d_{k}}{l_{0}}=p_{k}-p_{k+1}
$$

Therefore,

$$
i_{n}=E\left[i_{n, k}\right]=\sum_{k=0}^{n} i_{n, k} \cdot{ }_{1} f_{k} .
$$




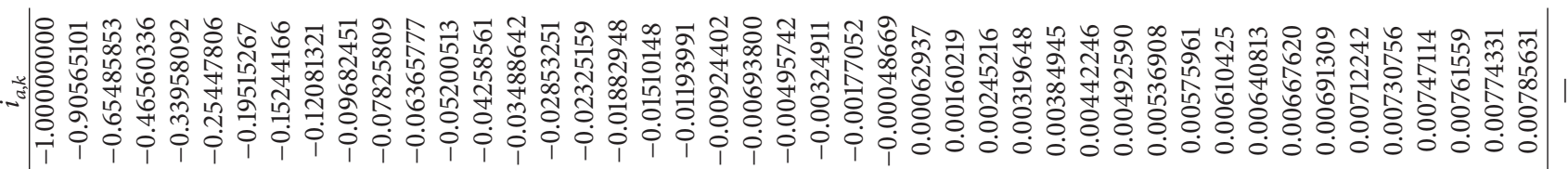

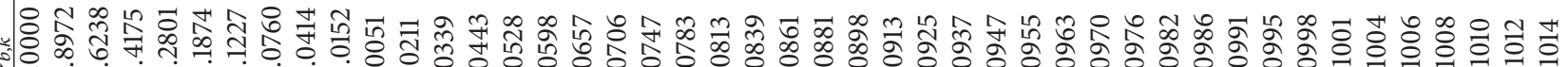

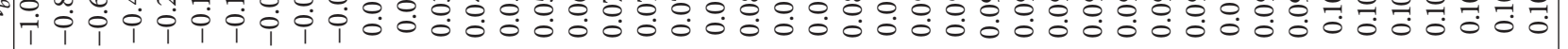

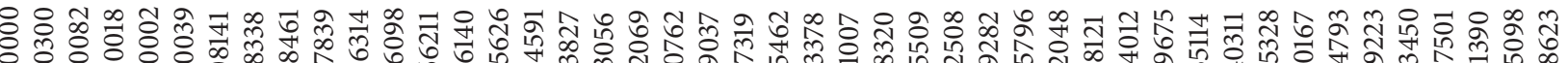

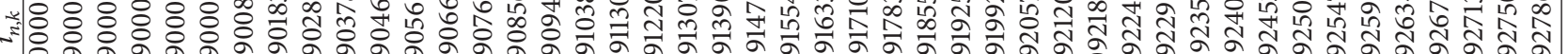

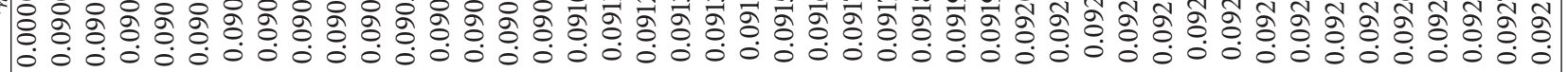

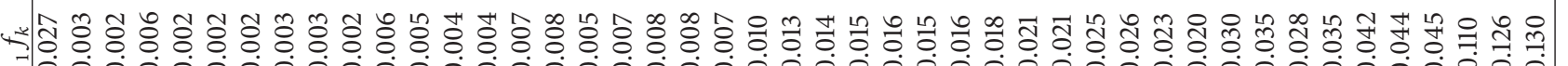

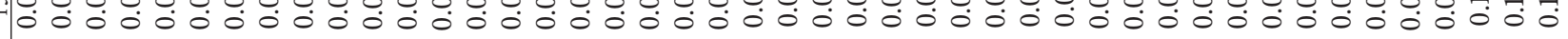

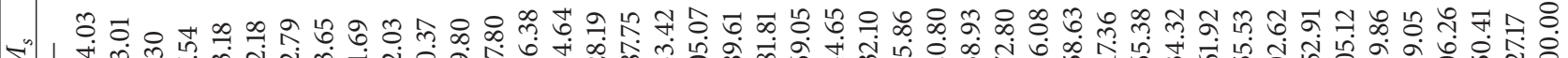

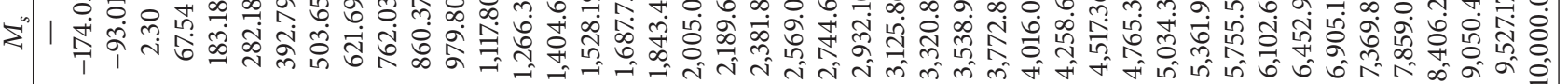

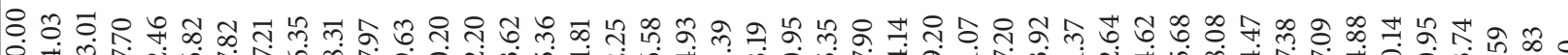

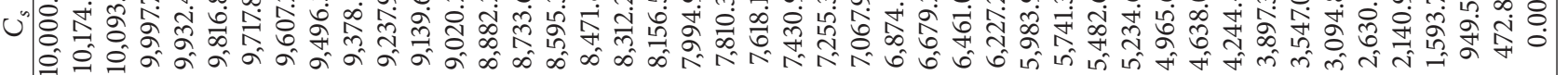
承 ष |

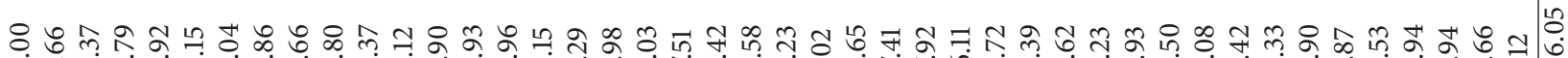

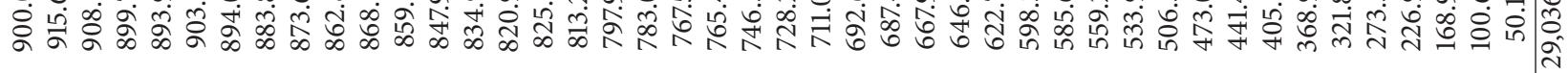

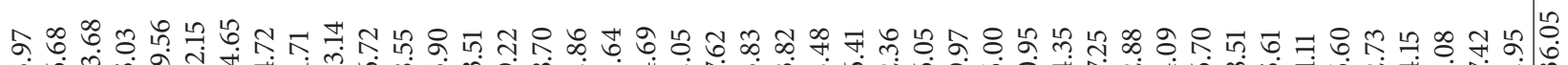

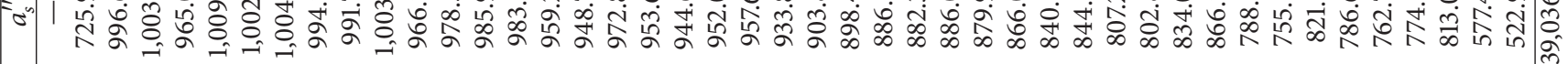

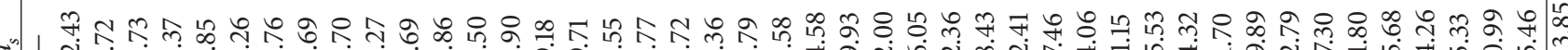

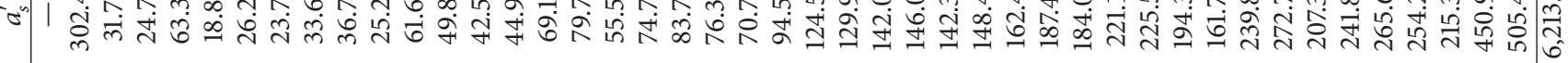

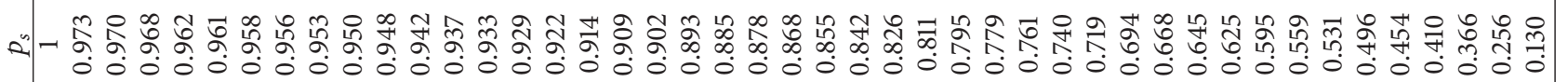

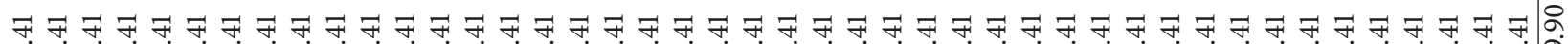

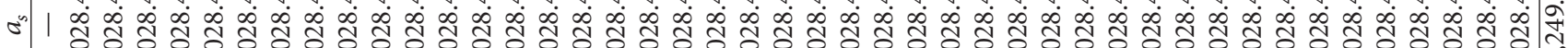

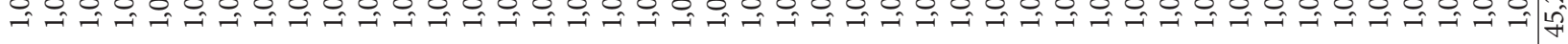

- 1 gे

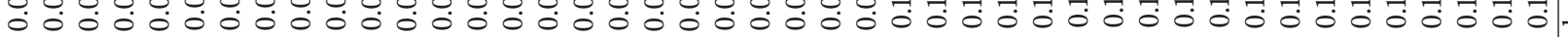


The interest rates corresponding to Example 1 appear in Table 1 and their expected average value is $8.9813 \%$.

(3) True Average Gross Interest Rate. Once the financial transaction has finished and then its maturity is well known, $i_{b, k}$ is said to be the true average gross interest rate if it makes the financial equivalence between the loan principal and the exact number, $k$, of periodic amounts paid by the borrower possible:

$$
C_{0}=\sum_{s=1}^{k} a_{s} \cdot\left(1+i_{b, k}\right)^{-s}
$$

Therefore, this rate is variable according to $k$ and $a$ priori, that is, at the beginning of the transaction, we can only estimate its mathematical expectation, taking into account the fact that the probability of $i_{b, k}$ is ${ }_{1} f_{k}$ and then

$$
i_{b}=E\left[i_{b, k}\right]=\sum_{k=0}^{n} i_{b, k} \cdot{ }_{1} f_{k} .
$$

Observe that $i_{b, k}$ can have a negative value if the last instalment of the loan repayment takes place before the amortization of the principal, that is to say, if

$$
C_{0}>\sum_{s=1}^{k} a_{s}
$$

The most extreme case occurs when the borrower dies even before the first repayment instalment is made. In this case, the lender does not receive any money and so $i_{b, 0}=-1$. This situation occurs with probability $1-p_{1}$. On the other hand, the maximum profitability is obtained when $k=n$, which occurs with probability $p_{n}$.

The true average gross interest rates of Example 1 appear in Table 1. Observe that, for the first nine years, the profitability will be negative, obtaining a positive profitability from year ten, and this is because

$$
\sum_{s=1}^{9} a_{s}=9,255.66<10,000.00<\sum_{s=1}^{10} a_{s}=10,284.07 .
$$

In this case, the expected average profitability of the financial transaction is $5.6 \%$ per year.

(4) Average Interest Rate due to Randomness. A relationship between the net and gross average rates can be established through the so-called average rate due to randomness (the concepts of the agreed average interest rate, true net interest rate, true gross interest rate, and average interest rate due to randomness coincide with the concepts of a priori average return, a posteriori average net return, a posteriori gross average return, and average return due to randomness introduced by Gil Peláez [19, pp. 539-542]), denoted by $i_{a, k}$, which is defined by means of the following equation:

$$
1+i_{b, k}:=\left(1+i_{n, k}\right) \cdot\left(1+i_{a, k}\right) \text {, }
$$

from which

$$
i_{a, k}=\frac{i_{b, k}-i_{n, k}}{1+i_{n, k}}
$$

Observe that $i_{a, k}$ will be negative provided that $i_{b, k}<i_{n, k}$, and this will occur when the transaction generates losses; that is to say, $R_{0, k}<0$. Analogous to the previously defined rates, this is variable depending on the duration of the financial transaction, so that its a priori expected average value can be calculated as follows:

$$
i_{a}=E\left[i_{a, k}\right]=\sum_{k=0}^{n} i_{a, k} \cdot{ }_{1} f_{k} .
$$

In Table 1, we can see the values corresponding to Example 1. In effect, for transaction with a duration of less than twentysix years, we will obtain losses with respect to a traditional (nonrandom) loan. So the average rate due to randomness would be negative. On the other hand, when the age of the borrower is equal to or greater than seventy-five years, the financial transaction would be profitable for the lender compared to the classical loan. Moreover, when the borrower is fifty-nine, the lender would recover the principal without any profit (interest). Finally, the expected average rate due to randomness is negative, more specifically $-3.324809 \%$.

At the beginning, when the contract is formalized, the loan duration is uncertain. Nevertheless, the probability distribution of the last repayment instalment is known so that we can determine its expected value, $\bar{k}$, in the following way:

$$
\bar{k}=E[k]=\sum_{k=0}^{n} k \cdot{ }_{1} f_{k} .
$$

In Example 1, the average duration estimated at the beginning of the transaction is 34.069 years, in which case the loan would finish when the borrower reaches the age of 83 .

Finally, the financial maturity of the transaction is defined as the duration of a fixed (nonrandom) transaction such that its net present value equals that of the random transaction, that is to say, the value $\widetilde{k}$ satisfying the following equation:

$$
C_{0}=\sum_{s=1}^{n} a_{s} \cdot p_{s} \cdot \prod_{h=1}^{s}\left(1+i_{h}\right)^{-1}=\sum_{s=1}^{\tilde{k}} a_{s} \cdot \prod_{h=1}^{s}\left(1+i_{h}\right)^{-1} .
$$

It is obvious that, in most cases, this equation does not have a solution within the set of integer numbers but we can find a value

$$
\tilde{k} \in[\alpha, \alpha+1[
$$

being

$$
\sum_{s=1}^{\alpha} a_{s} \cdot \prod_{h=1}^{s}\left(1+i_{h}\right)^{-1}<C_{0}<\sum_{s=1}^{\alpha+1} a_{s} \cdot \prod_{h=1}^{s}\left(1+i_{h}\right)^{-1} .
$$


In Example 1, the final repayment instalment of the transaction is included in the interval [25,26[, since

$$
\begin{aligned}
\sum_{s=1}^{25} a_{s} \cdot \prod_{h=1}^{s}\left(1+i_{h}\right)^{-1} & =9,957.38<10,000.00 \\
& <10,056.32 \\
& =\sum_{s=1}^{26} a_{s} \cdot \prod_{h=1}^{s}\left(1+i_{h}\right)^{-1} .
\end{aligned}
$$

Observe that, after the twenty-sixth year, the average interest rate due to randomness is positive. In effect, for durations longer than twenty-six years, the lender obtains a greater profit from a random transaction than that obtained from a fixed (nonrandom) transaction.

\section{Amortization of a Loan Transaction Where the First Repayment Instalment Is Random and the Last Is Fixed}

Using the same nomenclature as in Section 2, let us consider a loan transaction where the borrower receives the principal $C_{0}$ at instant 0 and later he/she pays $n$ periodic instalments $a_{s}$, on specified dates $s(s=1,2, \ldots, n)$ in order to amortize the principal. In this case, we are going to assume that the payment of the first instalment is subject to a contingency whereby the borrower will have to pay greater amounts $a_{s}$ than if the loan is not subject to this eventuality. Therefore, the equation of financial equivalence at the beginning of the transaction, by considering the exponential discount function at variable interest rate, is

$$
C_{0}=\sum_{s=1}^{n} a_{s} \cdot \prod_{h=1}^{s}\left(1+i_{h}\right)^{-1} \cdot\left(1+r_{h}^{\prime}\right)^{-1}
$$

where $r_{h}^{\prime}$ denotes the risk element which the borrower has to pay to the lender.

In the case of the aforementioned contingency being the death of the borrower, the risk represented by $r_{h}^{\prime}$ is the survival of the borrower which, consequently, causes a delay in the commencement of repayment instalments. An example of this situation is the case of a person who, on retirement, requests an inverse mortgage receiving a single amount and agreeing with the financial entity that its repayment is to be made by instalments by the heirs over an agreed period of time after the death of the borrower.

Thus, by considering the survival/death of the borrower, we have (see $[17$, p. 278])

$$
1+r_{h}^{\prime}=\frac{1}{{ }_{1} q_{h-1}}
$$

${ }_{1} q_{h-1}$ being the probability that a person aged $h-1$ dies before reaching the age $h$, where

$$
{ }_{1} q_{h-1}=1-{ }_{1} p_{h-1} \text {. }
$$

By considering (37), (38), and (39), one has

$$
C_{0}=\sum_{s=1}^{n} a_{s} \cdot \prod_{h=1}^{s}\left(1+i_{h}\right)^{-1} \cdot\left(1-{ }_{1} p_{h-1}\right) .
$$

Therefore,

$$
\begin{aligned}
C_{0}= & \sum_{s=1}^{n} a_{s} \cdot \prod_{h=1}^{s}\left(1+i_{h}\right)^{-1}-\sum_{s=1}^{n} a_{s} \cdot \prod_{h=1}^{s}\left(1+i_{h}\right)^{-1} \\
& \cdot{ }_{1} p_{h-1},
\end{aligned}
$$

from which, taking into account (1), (2), and (3), one has

$$
C_{0}=\sum_{s=1}^{n} a_{s} \cdot \prod_{h=1}^{s}\left(1+i_{h}\right)^{-1}-\sum_{s=1}^{n} a_{s} \cdot p_{s} \cdot \prod_{h=1}^{s}\left(1+i_{h}\right)^{-1}
$$

that is to say, the periodic payments where the first date of instalments is random and the last one is fixed can be obtained as the difference between a set of payments where the dates of the first and the last instalments are fixed and another one where the first date is fixed and the last one is random:

$$
C_{0}=C_{0}^{\mathrm{ff}}-C_{0}^{\mathrm{fr}},
$$

being

(i) $C_{0}^{\mathrm{ff}}=\sum_{s=1}^{n} a_{s} \cdot \prod_{h=1}^{s}\left(1+i_{h}\right)^{-1}$, where the dates of the first and last payments are fixed,

(ii) $C_{0}^{\mathrm{fr}}=\sum_{s=1}^{n} a_{s} \cdot p_{s} \cdot \prod_{h=1}^{s}\left(1+i_{h}\right)^{-1}$, where the date of the first payment is fixed and that of the last one is random.

The outstanding principal at an intermediate instant $k$ of the transaction, $C_{k}$, will depend on whether the periodic payments have or have not started at that instant. We will denote by $C_{k}^{\prime}$ the outstanding principal when the periodic payments have not yet started and by $C_{k}^{\prime \prime}$ the outstanding principal when the periodic payments have started. Thus, we have the following expressions according to the employed method.

(1) Prospective Method (according to the Future Amounts Still to Be Paid, That Is to Say, from Instant $k$ to the Last Date $n$ ). Here, we can consider the following two subcases:

(i) If, at instant $k$, the periodic payments have not yet started, then all future payments are random, so that

$$
C_{k}^{\prime}=\sum_{s=k+1}^{n} a_{s} \cdot \prod_{h=k+1}^{s}\left(1+i_{h}\right)^{-1} \cdot\left(1+r_{h}^{\prime}\right)^{-1},
$$

from which simple algebra shows that

$$
\begin{aligned}
C_{k}^{\prime}= & \sum_{s=k+1}^{n} a_{s} \cdot \prod_{h=k+1}^{s}\left(1+i_{h}\right)^{-1}-\frac{1}{p_{k}} \cdot \sum_{s=k+1}^{n} a_{s} \cdot p_{s} \\
& \cdot \prod_{h=k+1}^{s}\left(1+i_{h}\right)^{-1} .
\end{aligned}
$$


(ii) If, at instant $k$, the periodic payments have started, then all future payments after $k$ are fixed, so that

$$
C_{k}^{\prime \prime}=\sum_{s=k+1}^{n} a_{s} \cdot \prod_{h=k+1}^{s}\left(1+i_{h}\right)^{-1} .
$$

It is obvious that, a priori, it is not possible to know for certain when instant $k$ will occur, and consequently it will be only possible to give an average value of the outstanding principal:

$$
C_{k}=C_{k}^{\prime} \cdot p_{k}+C_{k}^{\prime \prime} \cdot\left(1-p_{k}\right)
$$

(2) Retrospective Method (according to the Periodic Amounts Repaid from the Start of the Transaction up to the Present). Analogously, we can consider here the following subcases:

(i) If, at instant $k$, the periodic payments have not yet started, then all payments whose dates belong to the interval $[0, k]$ will be zero, so that

$$
C_{k}^{\prime}=C_{0} \cdot \prod_{h=1}^{k}\left(1+i_{h}\right),
$$

and the probability of occurrence of this situation is $p_{k}$.

(ii) If, at instant $k$, the periodic payments have started, in this case, it is possible that

(1) the payments started in the first period, so that the outstanding principal, denoted by $C_{k, 1}^{\prime \prime}$, will be equal to

$$
C_{k, 1}^{\prime \prime}=C_{0} \cdot \prod_{h=1}^{k}\left(1+i_{h}\right)-\sum_{s=1}^{k-1} a_{s} \cdot \prod_{h=s+1}^{k}\left(1+i_{h}\right)-a_{k}
$$

and the probability of occurrence of this case is ${ }_{1} f_{0}=p_{0}-p_{1}$;

(2) the payments started in the second period, so that the outstanding principal, denoted by $C_{k, 2}^{\prime \prime}$, will be equal to

$$
C_{k, 2}^{\prime \prime}=C_{0} \cdot \prod_{h=1}^{k}\left(1+i_{h}\right)-\sum_{s=2}^{k-1} a_{s} \cdot \prod_{h=s+1}^{k}\left(1+i_{h}\right)-a_{k}
$$

and the probability of occurrence of this case is ${ }_{1} f_{1}=p_{1}-p_{2}$;

(k) the payments started in the $k$ th period, so that the outstanding principal, denoted by $C_{k, k}^{\prime \prime}$, will be equal to

$$
C_{k, k}^{\prime \prime}=C_{0} \cdot \prod_{h=1}^{k}\left(1+i_{h}\right)-a_{k},
$$

and the probability of occurrence of this case is ${ }_{1} f_{k-1}=p_{k-1}-p_{k}$.
By considering the expressions from (48) to (51), one has

$$
C_{k}=C_{k}^{\prime} \cdot p_{k}+\sum_{j=1}^{k} C_{k, j}^{\prime \prime} \cdot\left(p_{j-1}-p_{j}\right) .
$$

Nevertheless, taking into account that

$$
\begin{gathered}
\sum_{j=1}^{k} C_{k, j}^{\prime \prime} \cdot\left(p_{j-1}-p_{j}\right)=\sum_{j=1}^{k-1}\left[C_{0} \cdot \prod_{h=1}^{k}\left(1+i_{h}\right)-\sum_{s=j}^{k-1} a_{s}\right. \\
\left.\cdot \prod_{h=s+1}^{k}\left(1+i_{h}\right)-a_{k}\right] \cdot\left(p_{j-1}-p_{j}\right)+\left[C_{0}\right. \\
\left.\cdot \prod_{h=1}^{k}\left(1+i_{h}\right)-a_{k}\right] \cdot\left(p_{k-1}-p_{k}\right)
\end{gathered}
$$

and since

$$
\sum_{j=1}^{k}\left(p_{j-1}-p_{j}\right)=1-p_{k}
$$

doing some appropriate operations, this simplifies to

$$
\begin{aligned}
C_{k}= & C_{0} \cdot \prod_{h=1}^{k}\left(1+i_{h}\right)-\sum_{s=1}^{k-1} a_{s} \cdot \prod_{h=s+1}^{k}\left(1+i_{h}\right) \cdot\left(1-p_{s}\right) \\
& -a_{k} \cdot\left(1-p_{k}\right) .
\end{aligned}
$$

(3) Recursive Method (according to the Value of the Outstanding Principal Calculated at a Previous Date). Consider the following.

(i) If, at instant $k$, the periodic payments have not started, then $a_{s}=0$ for $s=1,2, \ldots, k$, so that

$$
C_{k}^{\prime}=C_{k-1} \cdot\left(1+i_{k}\right) \text {. }
$$

(ii) If, at instant $k$, the periodic payments have started (independently of the fact that they have started in the $k$ th period or earlier), then

$$
C_{k}^{\prime \prime}=C_{k-1} \cdot\left(1+i_{k}\right)-a_{k} .
$$

Consequently, by considering (47), (56), and (57), one has

$$
C_{k}=C_{k-1} \cdot\left(1+i_{k}\right)-a_{k} \cdot\left(1-p_{k}\right) .
$$

Starting from (58) and knowing that each instalment is the sum of the risk quota plus the saving quota

$$
C_{s}=C_{s-1} \cdot\left(1+i_{s}\right)-\left(a_{s}^{\prime}+a_{s}^{\prime \prime}\right) \cdot\left(1-p_{s}\right)
$$

and considering that the saving quota is

$$
a_{s}^{\prime \prime}=C_{s-1} \cdot\left(1+i_{s}\right)-C_{s},
$$

this can be simplified to

$$
a_{s}^{\prime}=a_{s}^{\prime \prime} \cdot \frac{p_{s}}{1-p_{s}} .
$$


Example 2. Assume that, in 2013, a person aged 50 requests a loan of $€ 10,000$, for the purchase of a parking space which itself serves as collateral. The loan principal will be amortized by his/her heirs after the death of the purchaser. The maximum duration of the transaction will be 40 years and the applicable annual interest rate will be $5 \%$ for the five first years, being updated every five years with an increase of $0.3 \%$. In order to determine the risk, the financial entity applies the generational tables of survival for males (tables PERM/F-2000P), according to which the person requesting the mortgage has at that moment a life expectancy of a further 27 years; that is to say, it is expected that the person lives to the age of 92 . The different parameters of the loan transaction can be observed in Table 2 .

In this kind of transaction it is also usual to find some periods in which the amortization "is not regular," that is to say, some periods in which the outstanding principal does not decrease as usual but increases since the corresponding instalment value is less than the sum of interest plus risk quota corresponding to the periods in question. This situation can be observed in the first twenty-two periods of our example in which the outstanding principal increases little by little until it amounts to $€ 15,687.64$.

With regard to the risk quota, this parameter diminishes with the progress of time and moreover the amount of decrease is progressively greater. This is logical because the probability of death of the borrower increases, reaching the value zero when the probability of survival of this person is zero. This occurs after the twenty-ninth year of the loan.

If death occurs in or before the sixteenth year of the loan, when the borrower will not have reached the age of 80 , then the total amount of payments made up to that time will yield a profit for the borrower which will be the same as that obtained from a fixed transaction (i.e., without consideration of the risk factor) since

$$
\begin{aligned}
10,000 \cdot \prod_{h=1}^{15}\left(1+i_{h}\right) & =21,697.41 \\
& <\sum_{h=16}^{40} 1,735.22 \cdot \prod_{h=16}^{s}\left(1+i_{h}\right)^{-1} \\
& =23,052.58 .
\end{aligned}
$$

In general terms, where $n$ is the number of agreed years and $\ddot{n}$ is the number of years during which the periodic payments are zero, it holds that

$$
C_{0} \cdot \prod_{h=1}^{\ddot{n}}\left(1+i_{h}\right)<\sum_{s=\ddot{n}+1}^{n} a_{s} \cdot \prod_{h=\ddot{n}+1}^{s}\left(1+i_{h}\right)^{-1} .
$$

Thus, if the payment of instalments has started before the sixteenth year of the loan, the profit obtained by the lender would be greater than that corresponding to a fixed (nonrandom) transaction. This will allow the lender to compensate for losses arising from other transactions, making the practical implementation of this kind of financial transaction attractive for many financial entities.
In this type of random loan, the following kinds of average interest rate can be defined.

(1) Average Agreed Interest Rate. If the loan is agreed with a variable interest rate, it is useful to calculate the average interest rate, $i_{m}$, resulting from the contract. By definition, this average is the rate which, if applied to all periods, makes it possible to calculate the periodic payments which amortize the initial loan plus accrued interest. Thus, once the values of $C_{0}, a_{s}$, and $p_{s}$ satisfying (42) have been determined, the average interest rate can be derived from the following equation:

$$
C_{0}=\sum_{s=1}^{n} a_{s} \cdot\left(1+i_{m}\right)^{-s}-\sum_{s=1}^{n} a_{s} \cdot p_{s} \cdot\left(1+i_{m}\right)^{-s}
$$

In Example 2, by considering that

$$
\begin{aligned}
10,000.00= & \sum_{s=1}^{40} 1,735.22 \cdot\left(1+i_{m}\right)^{-s} \\
& -\sum_{s=1}^{40} 1,735.22 \cdot p_{s} \cdot\left(1+i_{m}\right)^{-s},
\end{aligned}
$$

the average rate of the loan transaction is $5.6577 \%$.

(2) True Net Interest Rate. Once the commencement of the financial transaction is known (i.e., the agreed date of the first repayment instalment), the true net interest rate, denoted by $i_{n, k}$, can be calculated as the rate satisfying the following equation:

$$
\sum_{s=k}^{n} a_{s} \cdot \prod_{h=1}^{s}\left(1+i_{h}\right)^{-1}=\sum_{s=k}^{n} a_{s} \cdot\left(1+i_{n, k}\right)^{-s} .
$$

Knowing that the result of the transaction (profit or loss) measured in monetary units corresponding to the initial instant and for a duration of $n-(k-1)$ periods, $R_{0, k}$, is given by the difference

$$
R_{0, k}=\sum_{s=k}^{n} a_{s} \cdot \prod_{h=1}^{s}\left(1+i_{h}\right)^{-1}-C_{0}
$$

and by considering (66) and (67), one has

$$
C_{0}+R_{0, k}=\sum_{s=k}^{n} a_{s} \cdot\left(1+i_{n, k}\right)^{-s},
$$

and this justifies the label "net" for the rate $i_{n, k}$.

This rate is variable depending on the moment at which the transaction comes into operation. Thus, at the beginning of the transaction, one can only determine its expected average value, taking into account the fact that the probability of each duration $n-(k-1)$ and consequently of each rate is (observe that when the date of the first instalment is fixed and the last is random, the $k$ th payment will be the last one provided that the death of the contracting party occurs between the ages of $k$ and $k+1$; nevertheless, if the date of the first instalment is random and the last is fixed, the $k$ th 


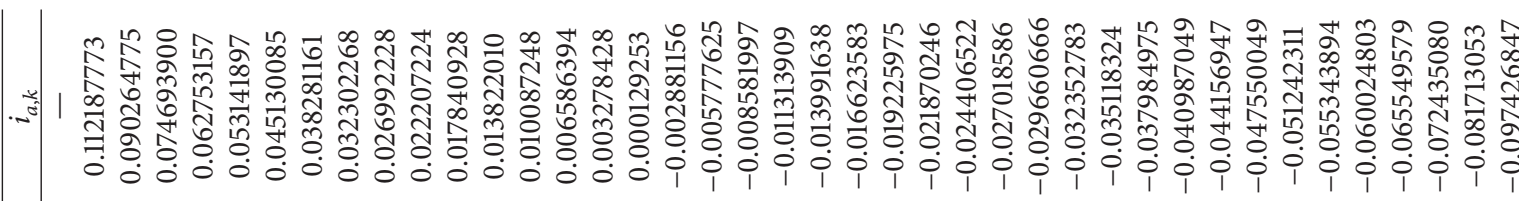

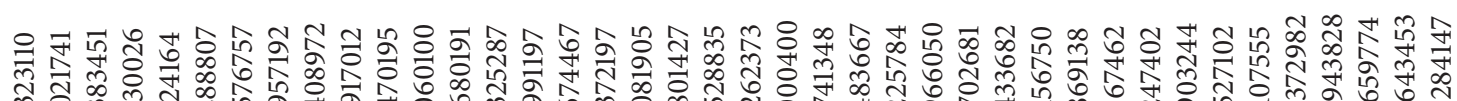

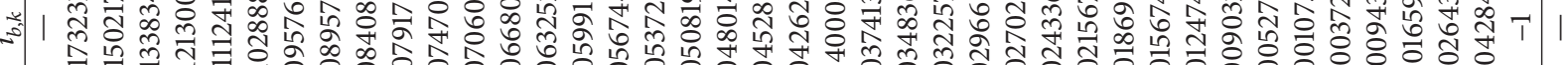

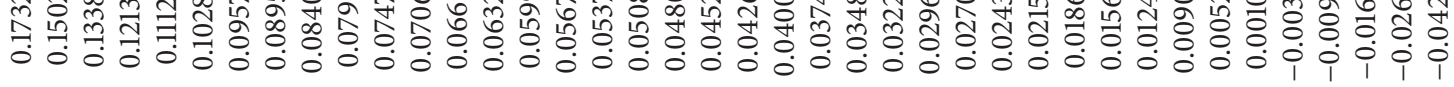

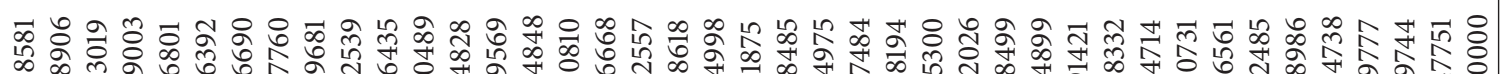

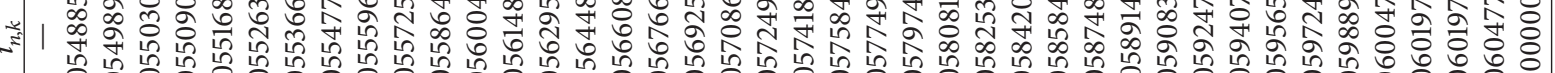

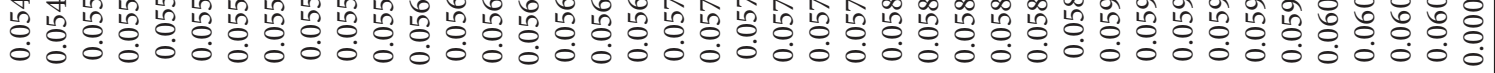

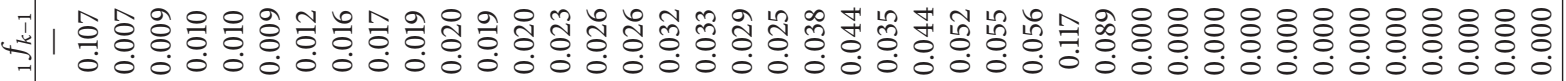

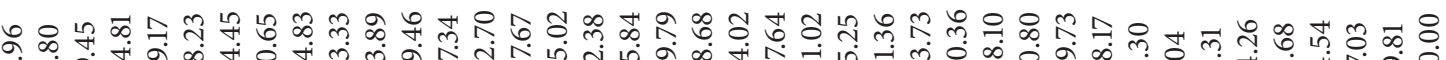

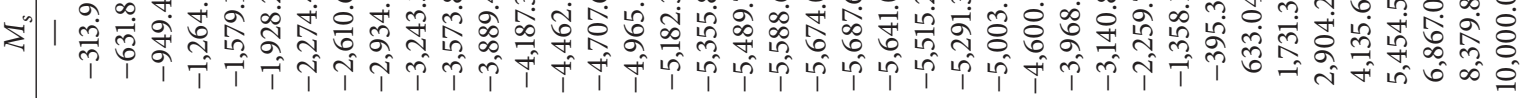

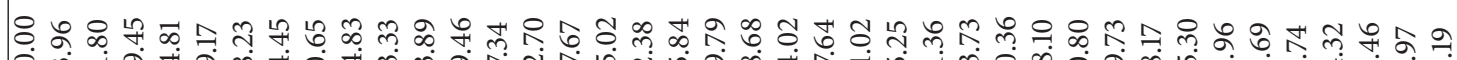

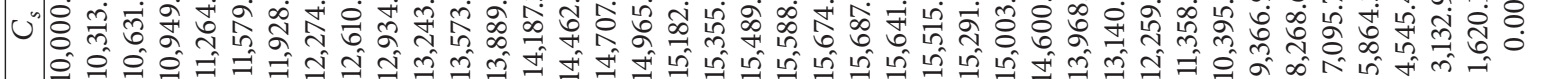

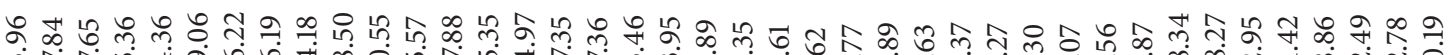

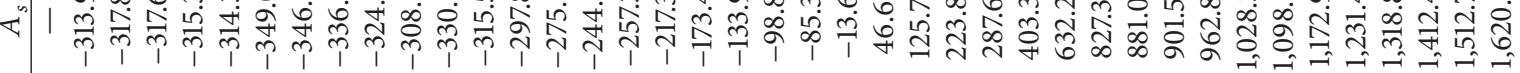

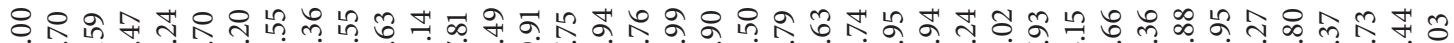

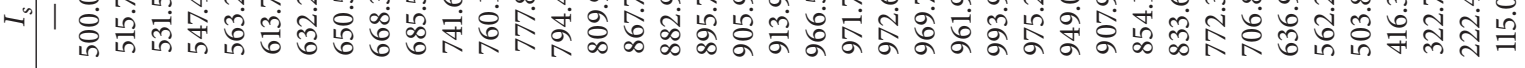

t艹 $=0 \mid \begin{array}{ll}0 \\ \infty\end{array}$

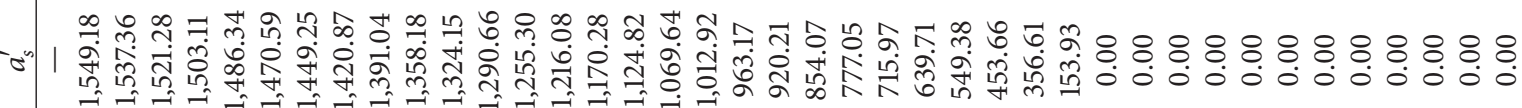

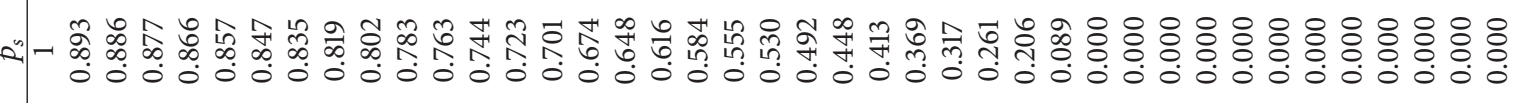

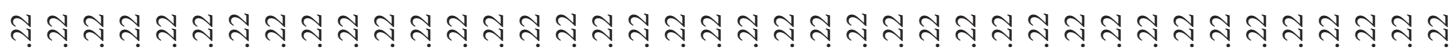

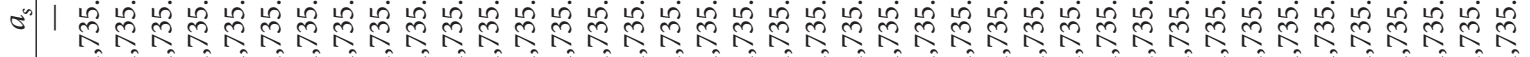

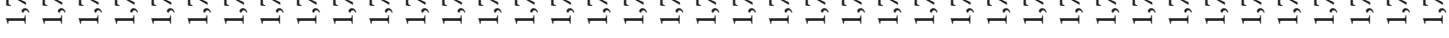

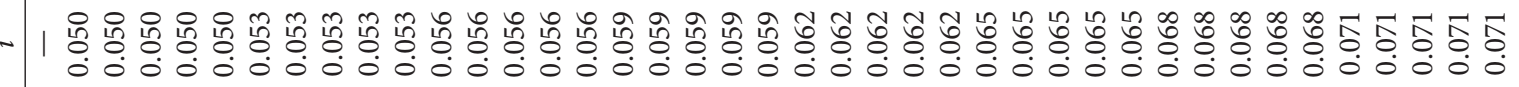
$\stackrel{\Xi}{\approx} \mid$ 
TABLE 3

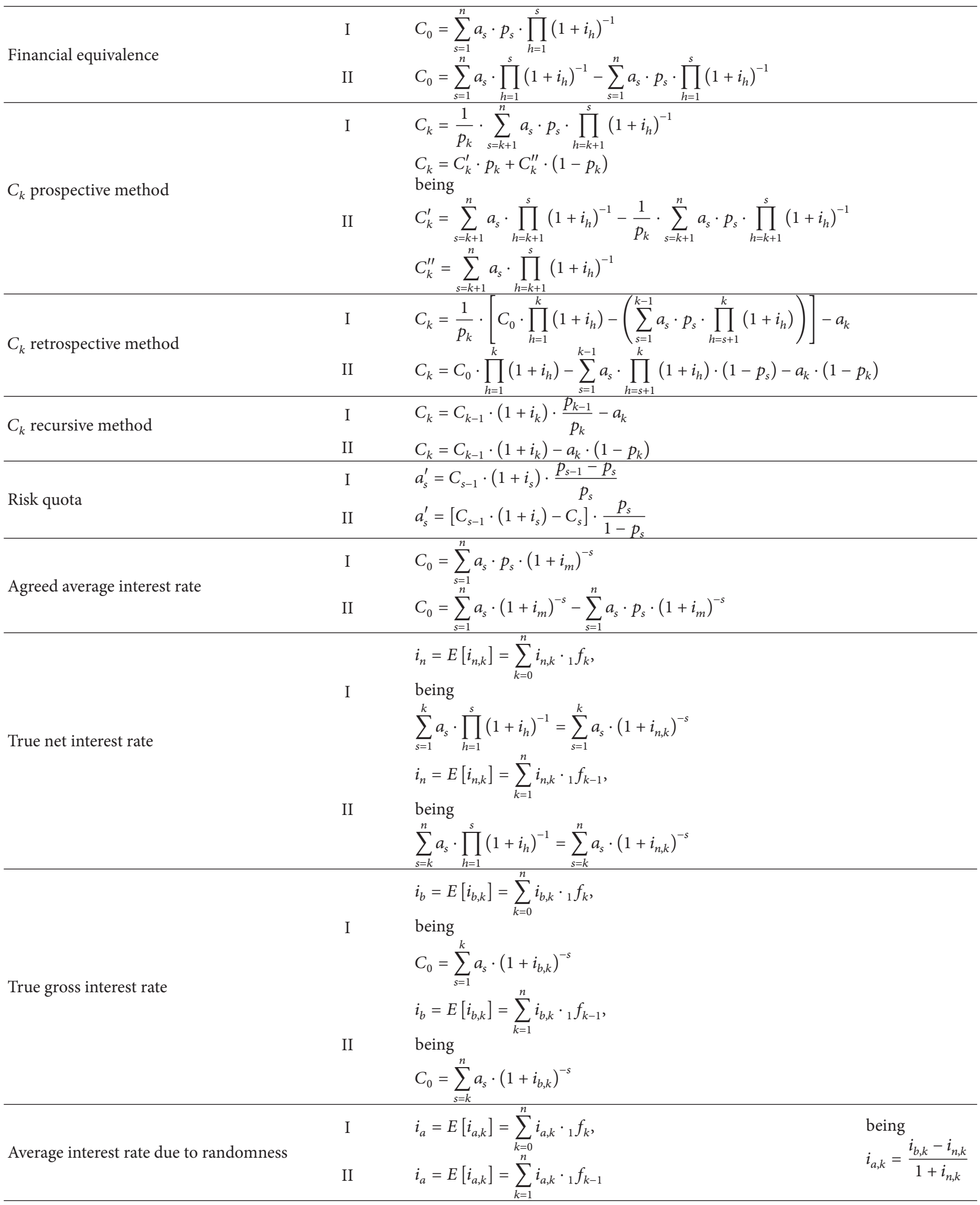


TABLE 3: Continued.

\begin{tabular}{lll}
\hline & I & $\bar{k}=E[k]=\sum_{k=0}^{n} k \cdot{ }_{1} f_{k}$ \\
Expected average last/first date & II & $\bar{k}=E[k]=\sum_{k=1}^{n} k \cdot{ }_{1} f_{k-1}$ \\
\hline Financial last/first date & I & $\sum_{s=1}^{\alpha} a_{s} \cdot \prod_{h=1}^{s}\left(1+i_{h}\right)^{-1}<C_{0}<\sum_{s=1}^{\alpha+1} a_{s} \cdot \prod_{h=1}^{s}\left(1+i_{h}\right)^{-1}$ \\
& II & $\sum_{s=\alpha}^{n} a_{s} \cdot \prod_{h=1}^{s}\left(1+i_{h}\right)^{-1}>C_{0}>\sum_{s=\alpha+1}^{n} a_{s} \cdot \prod_{h=1}^{s}\left(1+i_{h}\right)^{-1}$ \\
\hline
\end{tabular}

payment will be the first one if the death of the contract holder occurs between the ages of $k-1$ and $k$ )

$$
{ }_{1} f_{k-1}=p_{k-1}-p_{k}
$$

Thus,

$$
i_{n}=E\left[i_{n, k}\right]=\sum_{k=1}^{n} i_{n, k} \cdot{ }_{1} f_{k-1}
$$

The interest rates corresponding to Example 2 appear in Table 2, giving an expected average value of 5.1938\%. Observe that as the periodic payments have to start, in probabilistic terms, at most in the twenty-ninth year, starting from the thirtieth year the values of $i_{n, k}$ do not have any effect on the mathematical expectation since the corresponding probabilities $f_{1} f_{k-1}$ are zero.

In Table 2 , a row with the notation $n^{+}$has been included in order to indicate the maturity of the transaction and describe the situation for the duration of the loan period when the contracting party survives. This would imply that periodic payments have not yet started.

(3) True Average Gross Interest Rate. Once the financial transaction has finished and then its maturity is well known, $i_{b, k}$ is said to be the true average gross interest rate if it makes the financial equivalence between the loan principal and the periodic amounts paid by the borrower possible:

$$
C_{0}=\sum_{s=k}^{n} a_{s} \cdot\left(1+i_{b, k}\right)^{-s} .
$$

This rate is variable according to $k$ and $a$ priori, that is, at the commencement of the transaction, we can only estimate its mathematical expectation taking into account the fact that the probability of $i_{b, k}$ is ${ }_{1} f_{k-1}$ and then

$$
i_{b}=E\left[i_{b, k}\right]=\sum_{k=1}^{n} i_{b, k} \cdot{ }_{1} f_{k-1} .
$$

Observe that $i_{b, k}$ can have a negative value if the periodic payments start so late that it is not possible for the lender to recover the principal, and this occurs when

$$
C_{0}>\sum_{s=k}^{n} a_{s}
$$

in the most extreme case when the loan expiration is prior to the start of payments; in such a case, the lender does not recover any money and so $i_{b, 0}=-1$. The probability of occurrence of this fact, according to the actuarial tables, is zero, but in practice this situation is possible unless the first payment is agreed later than the first period for which the probability is zero. On the other hand, maximum profitability is obtained when $k=1$, that is to say, when the contract holder dies within the first year of the loan period.

The true average gross interest rates of Example 2 appear in Table 2. Observe that if the payments start in the thirtysixth period or later, the profitability will be negative, obtaining a positive profitability:

$$
\sum_{s=36}^{40} a_{s}=8,676.11<10,000.00<\sum_{s=35}^{40} a_{s}=10,411.32 .
$$

The expected average profitability of this transaction is $6.0088 \%$.

(4) Average Interest Rate due to Randomness. From (30), it can be seen that this rate is $i_{a, k}=\left(i_{b, k}-i_{n, k}\right) /\left(1+i_{n, k}\right)$.

Moreover, it is variable according to $k$, so that a priori we can only calculate its expected value:

$$
i_{a}=E\left[i_{a, k}\right]=\sum_{k=1}^{n} i_{a, k} \cdot{ }_{1} f_{k-1} .
$$

In Table 2, we can see the values corresponding to Example 2. In effect, the transaction must start at the latest by the sixteenth period because otherwise the lender will obtain losses with respect to the corresponding traditional (nonrandom) loan. Thus, for the considered case, its average value is $0.2830 \%$.

At the beginning, when the contract has been formalized, the date on which the first instalment falls due is uncertain. Nevertheless, its probability distribution is well known so that we can determine its expected value, $\bar{k}$, in the following way:

$$
\bar{k}=E[k]=\sum_{k=1}^{n} k \cdot{ }_{1} f_{k-1} .
$$

In Example 2, the estimated starting date of the periodic payments in this transaction is 18.597 years after agreeing the contract, whereby the periodic payments will start in the nineteenth year, when the subject dies at age 82-83. 
Finally, the financial commencement of the transaction is defined as the duration of a fixed (nonrandom) transaction such that its net present value is equal to that of the random transaction, that is to say, the value $\widetilde{k}$ satisfying the following equation:

$$
\begin{aligned}
C_{0} & =\sum_{s=1}^{n} a_{s} \cdot \prod_{h=1}^{s}\left(1+i_{h}\right)^{-1}-\sum_{s=1}^{n} a_{s} \cdot p_{s} \cdot \prod_{h=1}^{s}\left(1+i_{h}\right)^{-1} \\
& =\sum_{s=\widetilde{k}}^{n} a_{s} \cdot \prod_{h=1}^{s}\left(1+i_{h}\right)^{-1} .
\end{aligned}
$$

It is obvious that, in most cases, this equation does not have a solution within the set of integer numbers but we can find a value

$$
\widetilde{k} \in[\alpha, \alpha+1[
$$

such that

$$
\sum_{s=\alpha}^{n} a_{s} \cdot \prod_{h=1}^{s}\left(1+i_{h}\right)^{-1}>C_{0}>\sum_{s=\alpha+1}^{n} a_{s} \cdot \prod_{h=1}^{s}\left(1+i_{h}\right)^{-1} .
$$

In Example 2, the financial commencement of the transaction is included in the interval $[16,17[$, since

$$
\begin{aligned}
\sum_{s=16}^{40} a_{s} \cdot \prod_{h=1}^{s}\left(1+i_{h}\right)^{-1} & =10,032.65>10,000.00 \\
& >9,277.47 \\
& =\sum_{s=17}^{40} a_{s} \cdot \prod_{h=1}^{s}\left(1+i_{h}\right)^{-1}
\end{aligned}
$$

Observe that, after the seventeenth year, the average interest rate due to randomness is negative. In effect, this is the instant from which the lender obtains losses with the random transaction and consequently he/she does not obtain the desired profitability.

\section{Conclusion}

In this paper, we have introduced two new kinds of loan transaction based on the uncertainty of the first or the last date of the periodic instalments which the borrower has to pay to amortize the loan principal. More specifically, this randomness is linked to the life expectancy of the borrower. Nevertheless, any other risk can also be considered because our approach is general enough to consider other contingencies:

(i) Loan of type I: the date of the first repayment instalment is fixed (nonrandom) but the final date is random.

(ii) Loan of type II: the date of the first repayment instalment is random but the final date is fixed (nonrandom).

For each kind of new loan, we present the parameters which allow us to determine the evolution of these transactions and also those which represent a difference with the traditional loans agreed in practice. In this way, we start with the equation of financial equivalence which represents the starting point to calculate the traditional loan parameters and then we determine the risk quota (which is the additional amount that the borrower must pay with respect to a traditional loan transaction to compensate the lender for the assumed risk) and the outstanding principal at each moment. Likewise, if as is usually agreed these transactions are subject to variable interest rates, it is necessary to calculate several different average interest rates to indicate the profitability/cost obtained by the lender/borrower, respectively. Table 3 gives a summary of the calculations which are put forward in this paper.

\section{Competing Interests}

The authors declare that there are no competing interests regarding the publication of this paper.

\section{References}

[1] S. C. Rambaud, "A financial analysis of certain flexible loans: calculation of the average duration," International Journal of Economics and Finance, vol. 5, no. 4, pp. 53-60, 2013.

[2] D. Conley and J. Thompson, "The effects of health and wealth shocks on retirements decisions," Federal Reserve Bank of St. Louis Review, vol. 95, no. 5, pp. 389-404, 2013.

[3] J. K. Shim and J. G. Siegel, Financial Management, McGraw-Hill, New York, NY, USA, 3rd edition, 2007.

[4] A. S. Suárez Suárez, Decisiones Óptimas de Inversión y Financiación en la Empresa, Ediciones Pirámide, S.A., Madrid, Spain, 1991.

[5] Z. Bodie, A. Kane, and A. J. Marcus, Essentials of Investments, McGraw-Hill/Irwin, New York, NY, USA, 5th edition, 2004.

[6] A. De Pablo López, Matemática de las Operaciones Financieras, Tomos I y II, Universidad Nacional de Educación a Distancia (UNED), Madrid, Spain, 2000.

[7] T. J. Biehler, The Mathematics of Money. Math for Business and Personal Finance Decisions, McGraw-Hill, New York, NY, USA, 2008.

[8] L. J. Dettling and J. W. Hsu, “The state of young adults' balance sheets: evidence from the survey of consumer finances," Federal Reserve Bank of St. Louis Review, vol. 96, no. 4, pp. 305-330, 2014.

[9] L. Ferruz Agudo, Operaciones Financieras. Descripción, Análisis y Valoración, Ed. Ariel, S. A., Barcelona, Spain, 1994.

[10] J. Van Horne, Financial Management and Policy, Prentice Hall, Upper Saddle River, NJ, USA, 1997.

[11] R. Brealey and S. Myers, Principles of Corporative Finance, McGraw-Hill, New York, NY, USA, 2002.

[12] R. A. Brealey, S. C. Myers, and F. Allen, Principles of Corporate Finance, McGraw-Hill/Irwin, New York, NY, USA, 8th edition, 2006.

[13] F. Ayres, Mathematics of Finance, McGraw-Hill, New York, NY, USA, 1963.

[14] S. Cruz Rambaud and M. C. Valls Martínez, Introducción a las Matemáticas Financieras, Ediciones Pirámide, S.A., Madrid, Spain, 2008.

[15] S. Cruz Rambaud, J. González Sánchez, and J. García Pérez, "Loans amortization with payments constant in real terms," 
Anales de Estudios Económicos y Empresariales, vol. 18, pp. 173189, 2008.

[16] S. Cruz Rambaud and J. González Sánchez, "Control in loan transactions: adjusting the payments to the real inflation rates," Control and Cybernetics, vol. 42, no. 4, pp. 829-853, 2013.

[17] M. C. Valls Martínez and S. Cruz Rambaud, Operaciones Financieras Avanzadas, Ediciones Pirámide, S. A., Madrid, Spain, 2013.

[18] M. A. Gil Luezas and L. Gil Peláez, Matemáticas de las Operaciones Financieras, Universidad Nacional de Educación a Distancia, Madrid, Spain, 1987.

[19] L. Gil Peláez, Matemática de las Operaciones Financieras, Editorial AC, Madrid, Spain, 1992.

[20] J. Dhaene, M. Goovaerts, M. Vanmaele, and K. Van Weert, "Convex order approximations in the case of cash flows of mixed signs," Insurance: Mathematics and Economics, vol. 51, no. 2, pp. 249-256, 2012.

[21] E. F. Brigham and P. R. Daves, Intermediate Financial Management, Thomson/South-Western, Mason, Ohio, USA, 9th edition, 2007. 


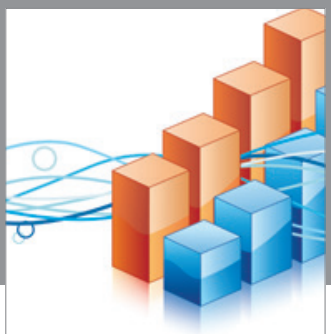

Advances in

Operations Research

vatem alat4

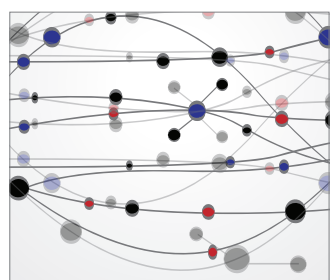

\section{The Scientific} World Journal
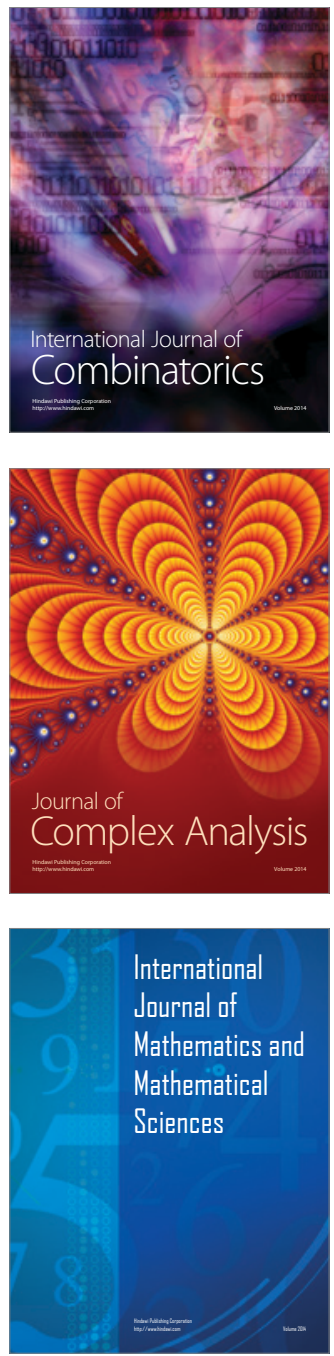
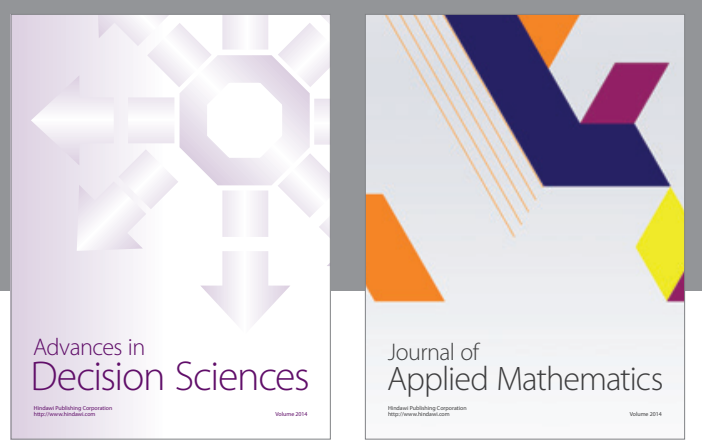

Algebra

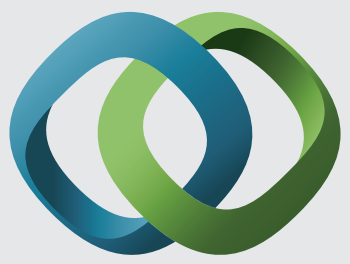

\section{Hindawi}

Submit your manuscripts at

http://www.hindawi.com
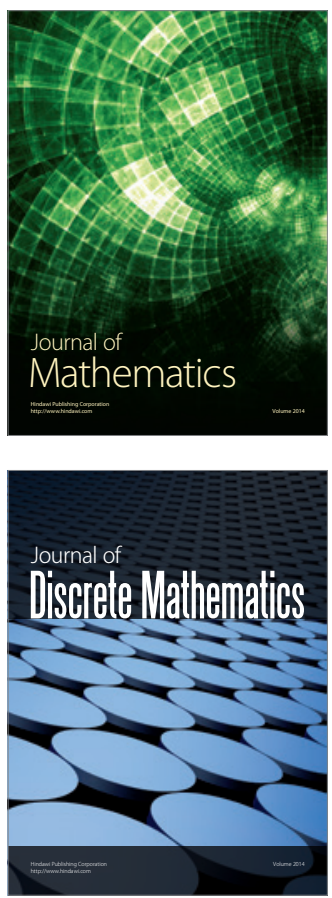

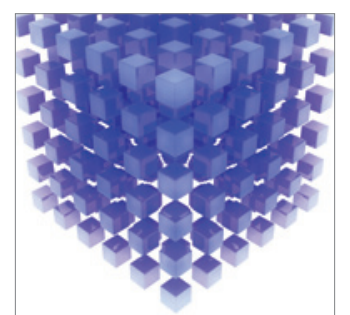

Mathematical Problems in Engineering
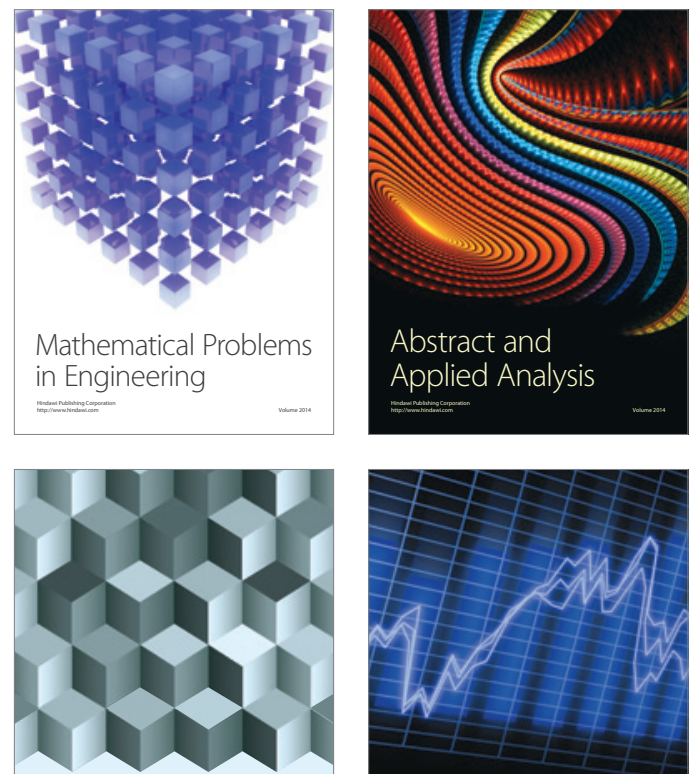

Journal of

Function Spaces

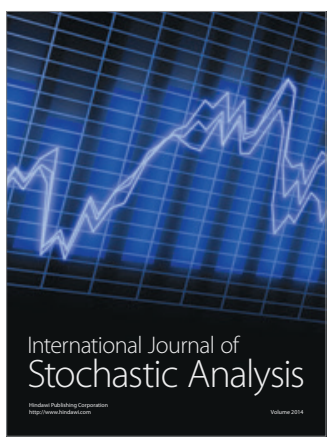

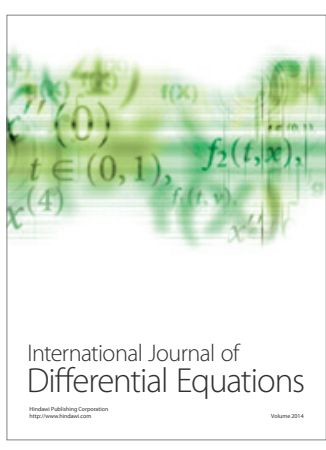
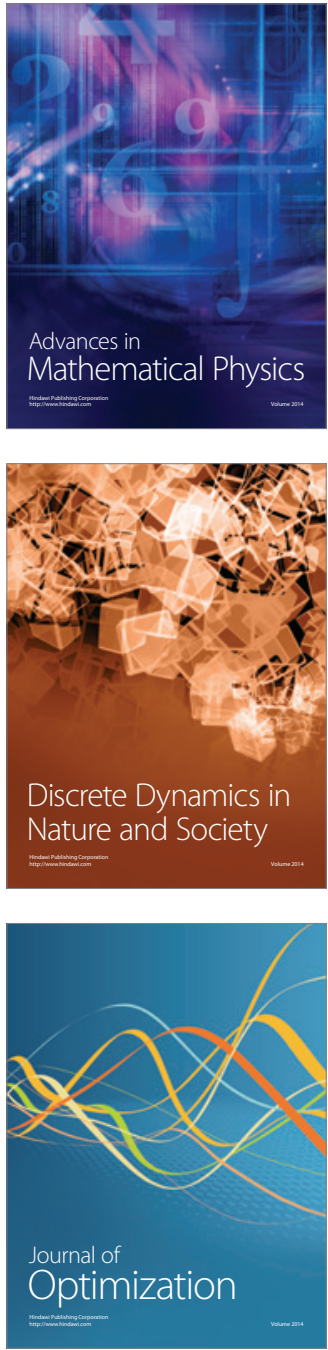